\title{
AN EVALUATION OF THE STIMULANTS AND IMPEDIMENTS TO INNOVATION WITHIN PFI/PPP PROJECTS
}

David Eaton', Rifat Akbiyikli, \& Michael Dickinson.

BuHu (Built \& Human Environment) Research Institute, Bridgewater Building, University of Salford. M7 1NU. UK.

\section{1 d.eaton@salford.ac.uk}

Tel: 01612955222

Submitted to CONSTRUCTION INNOVATION 29/03/05

Revised after reviewers comments 23/09/05

Revised after reviewers comments 14/10/05

Accepted 31/01/06 


\title{
AN EVALUATION OF THE STIMULANTS \& IMPEDIMENTS TO INNOVATION WITHIN PFI/PPP PROJECTS
}

\begin{abstract}
This paper identifies the theoretical stimulants and impediments associated with the implementation of PFI/PPP (Private Finance Initiative/Public Private Partnership) projects. A current defect of this procurement approach is the unintentional constraint upon the innovations incorporated into the development of PFI projects. A critical evaluation of the published literature has been utilised to synthesise a theoretical model. The paper proposes a theoretical model for the identification of potential innovation stimulants and impediments within this type of procurement. This theoretical model is then utilised to evaluate four previously completed PFI projects. These project case-studies have been examined in detail. The evaluation demonstrates how ineffective current procedures are.
\end{abstract}

The application of this model before project letting could eliminate unintentional constraints and stimulate improved innovation within the process. The implementation of the model could improve the successful delivery of innovation within the entire PFI/PPP procurement process.

Keywords: PFI; PPP; Innovation Stimulants; Innovation Impediments.

\section{INTRODUCTION}

The competitive advantage of organisations has traditionally depended on such factors as possession of assets, economies of scale and access to capital. However, increasingly intense competition and turbulent market environments are forcing organisations to rethink the way in which they manage and conduct their business. The survival and success of organisations in such climates is repeatedly suggested to depend on creativity and innovation (Kanter, 1983; Drucker, 1986; Porter, 1990; Geroski, 1994; DeGraff and Lawrence, 2002).

As creativity and innovation become increasingly important to company performance, both practitioners and researchers have sought ways to increase the occurrence of these activities. Some attempts to improve innovative activity have turned to traditional creativity research (Guilford, 1959; Barron, 1969; Barron and Harrington, 1981; Stein, 1991) that focuses on the traits and personal characteristics of individuals. However, adopting such an approach has been criticised as being entirely asocial and of only limited value to understanding the development of innovations in complex social systems, such as organisations (King, 1990; Woodman et al., 1993; Csikszentmihalyi and Sawyer, 1995).

To take understanding of the development of creativity and innovation beyond the limited trait centred base, research from a social perspective that considers both people and their environment is demanded. A research theme has emerged that responds to this need. Aiming to deliver a more complete understanding of creativity and innovation, research investigating the influence of the work environment on innovative behaviour in organisations has developed (Amabile, 1983; 1996, Amabile 
et al., 1986; 1996, Woodman et al., 1993; Anderson and West, 1994; Oldham and Cummings, 1996; Isaksen et al., 2001).

Research into the effects of the working environment on creative and innovative behaviour has produced strong findings that suggest that innovation can be increased in organisations through the management of variables that influence behaviour (Woodman et al., 1993; Amabile et al., 1996; Oldham and Cummings 1996). Specifically, the research identifies that variables in the form of social influences (such as organisational culture and climate) and contextual issues (such as task and time constraints) act as either stimulants or impediments to the creative behaviour of individuals in organisations. The proposition is subsequently made that successfully managing influences in the working environment of organisations can increase the level and frequency of creative and innovative behaviour (Amabile et al., 1996).

The specific focus of this research lies with the social and contextual factors that influence the creative and innovative behaviour of individuals in construction organisations within the limited and constrained context of the PFI (Private Finance Initiative) project. No study investigating the influence of work environment factors on the creativity of individuals has been undertaken in this context. This paper is part of a larger research agenda that addresses this shortfall. In doing so the research will highlight how imperative the understanding of situational variables that influence creative and innovative behaviour is to improving the management of innovation in PFI.

The desire for innovation in the construction industry is well recognised (e.g. Atkin, 1999; Manseau and Seaden, 2001). In response to the findings of keynote reports by Latham (1994) and Egan (1998) a host of UK (United Kingdom) government supported initiatives and programmes have been established to drive radical improvements in construction, including the Construction Research and Innovation Strategy Panel (CRISP), Partners in Innovation (PII) and Movement for Innovation (M4i).

In addition, Eaton (2001) declares, "without innovation a business does not have a rational source of competitive advantage in construction". Gann (2000) comments that construction firms need to improve their capabilities in managing innovation if they are to "build reputations for technical excellence that set them apart from more traditional players". Moreover, Barrett et al (2001,) remark that successful innovation enables construction firms to better satisfy "the aspirations and needs of society and clients, whilst improving their competitiveness in dynamic and abrasive markets". A critical factor claimed for PFI is the ability to bring improved innovation into the project delivery. To date no substantive research has been identified to confirm or refute this claim.

There is a substantial and varied body of general management and psychological research that has investigated the concept of innovation. However, whereas the mainstream innovation literature is vast, research into innovation in the context of construction is sparse. Barrett et al., (2001) assert that research into innovation in construction is not specific to the industry and still very much in its embryonic stage. Egbu et al. (1998) observe that: 
"There still remains a great deal to be investigated and learned about organisational innovations within a construction environment. This is more so within the management domain of innovation where there is still a meagre amount of empirical studies that have given attention to the innovations in construction enterprises."

Winch (1998) echoes this view and suggests that much more innovation research is required to "get a grip on the sources and applications of new ideas in the construction industry”.

The scope of this research lies with the social and contextual influences that act as either stimulants or impediments to creativity in PFI construction. The definition of construction and the construction industry used in this study follows Eaton (2000):

"Construction industry: taken in its broadest sense to include all built structure and the professional services necessary to execute such work. It would include, inter alia, house-building, building and civil engineering, power, process and heavy engineering, the built environment professions including architecture and the RIBA, surveying and the RICS, building and the $C I O B$, engineering and the ICE, I Struct. E, CIBSE et al."

PFI is a limited market segment of the construction industry. However, because of the nature of the PFI arrangement a PFI 'project' could involve any part of the construction industry, and as such it is a useful microcosm of the entire construction industry defined above.

The objectives of the research are as follows:

1. To identify potential stimulants to creativity in PFI construction;

2. To identify potential impediments to creativity in PFI construction;

3. To develop a theoretical model for the PFI construction industry of potential stimulants and impediments to creative behaviour in construction;

4. To evaluate the innovation incorporated within PFI by an evaluation of four previous case studies of PFI delivery;

5. To present recommendations on how to improve the incorporation of innovation within PFI/PPP project delivery.

The first phase of the research involves a review of construction innovation literature and general creativity and innovation research from the disciplines of organisational behaviour, management science and social psychology. The review of the literature fields leads to the development of a theoretical model of stimulants and impediments to creativity. Subsequent phases of the research involve the utilisation of four previous PFI case studies utilising text analysis of semi-structured interviews with senior construction industry practitioners and field-notes of interviews with client, SPV (Special Purpose Vehicle) and contractor representatives. An innovation 
evaluation is conducted to verify and evaluate the incorporation of innovation in the four projects presented. Details of the innovation protocol are provided later.

\section{LITERATURE REVIEW}

The following section presents a review of the literature related to the creative and innovative behaviour of individuals in organisations. It firstly introduces the context of creativity and innovation in this research. A broad outline of creativity is then presented through exploration of the people, process and product aspects of creativity before attention is turned to the work environment influences on creativity. This examination of the social and contextual influences on creativity is divided into four hierarchical levels: firstly the job role level, secondly the project team or group level, thirdly the organisation level and fourthly the environment external of organisations. This is considered to be an ascending organisational hierarchy, although no evaluation of this assumption is presented within this paper. A review of construction literature is then presented with particular attention paid to the increasing construction innovation literature.

There are numerous definitions of creativity and innovation in the literature and no obvious agreement amongst researchers and practitioners on the precise content of the two concepts. Indeed, several commentators use the two terms interchangeably. However, a common theoretical standpoint is that creativity is the initial stage of innovation and that all innovation begins with a creative idea from an individual or team (Zaltman et al., 1973; Amabile, 1988; Amabile et al., 1996; West, 2001). Such a position is adopted in this study and four assumptions underpinning and guiding this research are summarised below:

- Creativity is the generation of creative ideas;

- Innovation is the successful implementation of creative ideas;

- For something to be classified as creative it has to be novel to only the unit of adoption be it the individual, project team or organisation;

- Anybody in any role (and at any hierarchical level) can be creative and have creative ideas.

A creative idea from an individual that begins the innovation process might be a completely original and novel idea that has never been contemplated before or it might be an idea acquired from elsewhere that can still be classified as creative if it is new and novel to the organisation in question. It is people who are creative and it is people who generate, modify and exploit ideas and because of this the study of individual creativity amongst employees is a vital element of investigations into innovations in organisations (Van de Ven, 1986; Scott and Bruce, 1994).

The environment external to the individual is acknowledged by commentators to have considerable influence on creative behaviour and innovation and can be divided into four categories:

- Job role level - hence impediments and/or stimulants arising from the individual;

- Project level - impediments and/or stimulants arising beyond the individual, but inside of the project team; 
- Organisation level- impediments and/or stimulants arising outside of the immediate project team but inside the organisations associated with the projected;

- Environment level - impediments and/or stimulants arising external of the organisations associated with the project.

These levels have been assimilated from the detailed examination of the literature and categorised in a hierarchical form depending upon the proximity of the influence to the individual innovator. Hence environmental level stimulants are more remote from the innovator than project level stimulants. Job Role Level impediments are more obvious because of there closer proximity to the innovator. However, the effect of a stimulant or obstacle is not proportionally related to the hierarchical position. This theoretical model was presented to a panel of PPP/PFI practitioners at a workshop event and the practitioners concluded that the hierarchical structure was a useful mechanism for categorising and positioning individual stimulants and impediments. The individual stimulants and impediments, at the four different levels of analysis, can be seen to be the social and contextual variables that combine with the personal characteristics of individuals to produce the drive for creativity in individuals. The four levels of variables illustrated will become the prime focus of the paper.

The generation of the creativity ideas that are vital for innovation and problem solving in organisations can be seen to be a complex combination of both people and the four levels of influences in the work environment.

It is also necessary to undertake a review of the specific construction innovation literature because the context of construction innovations can differ significantly from a great proportion of manufacturing innovations (Slaughter, 1998). There is a growing interest in innovation in construction (Nam and Tatum, 1997; Slaughter, 1998, 2000; Atkin, 1999; Winch, 1998; Gann 2000; Manseau and Seaden, 2001; Sexton and Barrett 2003) and several recent studies (Egbu et al., 1998; Barrett et al., 2001; Dulaimi et al., 2002) have been undertaken to investigate innovation further.

Sturges et al. (1999) state "it is often said that the construction industry is not very innovative" and Winch (2003) notes that "construction is commonly characterized as a 'backward industry', and in particular, one that fails to innovate in comparison to other sectors" however, the widespread perceptions identified by the authors do not do justice to the importance of innovation in the industry. Innovation in the construction industry is important for several reasons.

For construction companies innovation is important because there are pressures from clients to improve quality, reduce costs and speed up construction processes (Gann, 2000). The benefits of innovation in construction include the improvement of working conditions, lower construction costs, quicker construction times and better value for clients. Furthermore, innovation in construction is now being advanced as the fourth competitive dimension to be added to the existing dimensions of cost, quality and time (Newton, 1999). However, innovation is not solely about competition and organisational performance and as Gann (2003) points out "issues of customer choice, social and environmental sustainability and quality of life are equally important”. 
When highlighting the importance of innovation construction keynote reports, including Latham (1994), Egan (1998) and Fairclough (2002), have suggested several problems in the construction industry that could be overcome through innovation and creative problem solving. The findings of the Egan report (1998) called for:

- Increased turnover and profitability for construction organisations;

- Increased productivity at all levels;

- An increased number of projects to be completed on time and within budget;

- A reduction in capital construction costs;

- A reduction in the time from client approval to practical construction;

- A reduction in the number of defects on hand-over by contractor to the client.

For the reasons outlined, the increase of innovative activity is now a priority and the challenge construction firms' face is identification of methods to improve the management of innovation in the industry. Following on from the propositions made in creativity research (Woodman et al., 1993; Amabile et al., 1996; Oldham and Cummings, 1996) the effective management of work environment influences on individual creativity has to be considered as one of the methods that can help to improve the management of innovation and assist in realising the benefits innovation can bring.

From a construction perspective Egbu et al. (1998) recognise the importance of the work environment to innovation "developing and sustaining a climate and culture of innovation is vital for long term sustenance of innovation within construction organisations" and also note that "Sustaining the right culture [for innovation] needs a supporting environment and successful innovations depend on having a supporting organisational context in which creative ideas can emerge and be effectively deployed".

Following the same division of work environment influences on individual creativity into the four levels of analysis that were outlined in the review of the general creativity research earlier, the construction innovation literature is reviewed below.

The construction literature provides insight into a number of possible variables from the environment external of construction organisations that could influence creative and innovative behaviour. Government is referred to by a number of sources as an important variable with regards to innovation in construction. Gann (2000) comments, that government has a key role to play in promoting and supporting innovation in the production of the built environment. Winch (2001) provides a review of public policy instruments that have been deployed to stimulate the rate and direction of innovation in the British construction industry. In addition, the extent to which the construction industry is regulated by government can also have an influence on innovation (Gann, 2000; Pries \& Janszen, 1995) and it is argued that organisations having to conform to planning legislation, and that building regulations can inhibit innovation (Sturges et al., 1998).

The coalition nature of construction companies during projects is also argued to influence the development of improvements and innovation (Egan, 1998). The collaborative engagement with other firms on projects means that almost all innovations in construction have to be negotiated between one or more actors (Winch, 1998). The supply chain is also recognised as being a notable influencer on 
construction innovation (Gann, 2000; Cooper et al., 2003) with component suppliers being identified as a major innovation source (Pries and Janszen, 1995). Other variables in the construction dynamic that can influence innovation include professional bodies (Robertson et al., 1997) and clients (Winch, 1998). The requirements of clients can drive the creative ideas and innovative designs that are necessary to deliver some projects, whilst clients can also constrain creative proposals if they are not prepared to take the risk of innovating (Nam and Tatum, 1997).

Turning to the organisational level of analysis Egbu et al. (1998) examined the management of innovation in construction by an in depth investigation of four companies in the industry that have won innovation awards. The study identified certain characteristics shown by all of the innovative organisations and these included:

- a culture where people are open-minded, willing to accept change, flexible, and free from dogma;

- flexibility in the lines of communication, structures that allow top-down, bottom- up and lateral communication within the organisation;

- a risk-tolerant climate where it is accepted that lessons can be learned through mistakes;

- a 'knowledge-friendly culture' where people are not inhibited about sharing knowledge and do not fear that sharing knowledge cost them 'power and influence' or even their jobs.

Tatum (1989) found that firms that foster innovation have organisational structures that maintained flexibility in size to allow focus on innovation. Dulaimi et al. (2002) found that successful innovation may come about if companies establish a reward system to recognise innovators and to promote future innovation and this is also supported by Egbu et al. (1998).

At the project level of analysis Dulaimi et al. (2002) also found that increased cooperation among organisations involved in construction to co-ordinate innovation efforts within particular projects may lead to successful innovation. From research in the construction domain the influence of trust in projects must also be identified as a potential variable for creative idea sharing and innovation (Swan et al., 2001). Support or lack of support from management and/or colleagues is a project level influence identified by Egbu et al. (1998).

At the work role level of analysis Dulaimi et al. (2002) found that companies should give employees freedom in their workload so that they have an opportunity to develop and experiment with new ideas. Egbu et al. (1998) noted that training and development can play an important role in the development of innovation, whilst a lack of coherent information and/or a lack resources, such as finance, can be impediments to creative idea development.

\section{THEORETICAL MODEL DEVELOPMENT}

Based upon the established literature a hierarchical model of stimulants and impediments are presented in Table 1 below. The individual features and hierarchical structure have been derived from the literature review. 


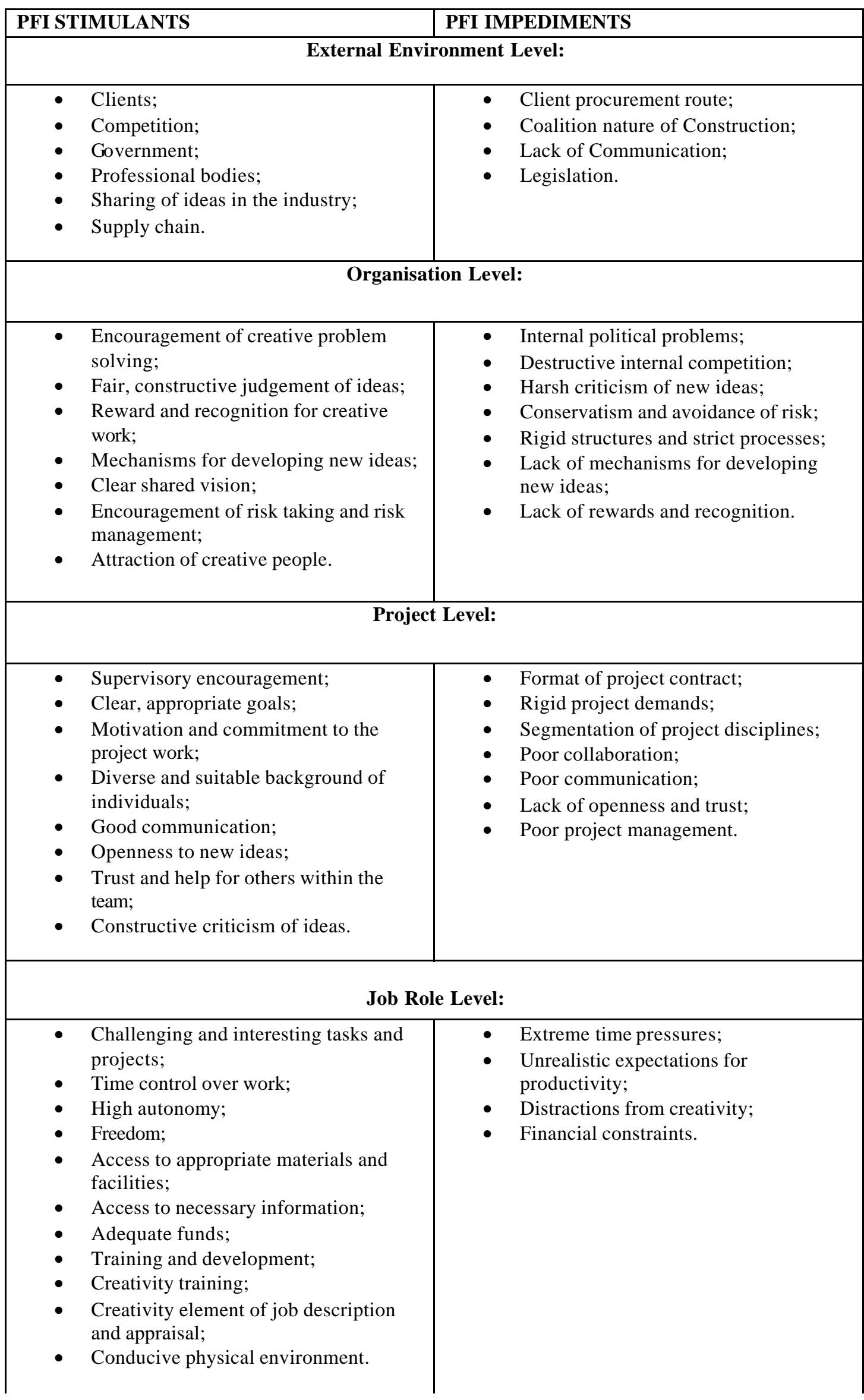

Table 1: PFI Theoretical Stimulants and Impediments 
These stimulants and impediments were then utilised in the examination and evaluation of detailed case studies. The case studies were two UK Prisons (combined as one study), a Portuguese Bridge, a UK Military development, and a very small UK 'unbundled' primary school. (Eaton, 2001; 2005, De Lemos \& Eaton, 2003; 2004.) These case studies have not been articulated in this paper. Each case study has been examined in detail and the innovation stimulants and impediments present within each project have been identified. The identification of the relevant features has been conducted independently of the case-study compilation by a researcher having no affiliation with any party associated with the projects. A feature is only identified if it creates a 'significant' difference to the more 'traditional' approach to contracting the built facility. The detailed feature identification of stimulants is provided in Table 2 and the detailed feature identification of impediments is provided in Table 3. Thus a feature has been identified only if the two following conditions of the research protocol are met:

The feature has materially affected the risk neutrality of the project;

The feature has materially affected the substantive completion on time, to quality and to price.

Risk neutrality is defined as the basis of agreement for contract closure. Thus it is the aggregation of all of the terms and conditions negotiated. It therefore defines the contractual position of all the parties before delivery of the project. Thus a stimulant is a feature that has a positive effect on the positions of the parties. It may be that an innovation feature can deliver project operation before the target completion date, or it may create a cost saving on the original design that can be shared between the parties. In these circumstances when a stimulant was found to be present in a particular case study a (•) is shown in Table 2 against the identified feature. An obstacle has a negative effect on the project and when found to be present on a particular project it is indicated by an (x) in Table 3.

The four case studies have then been evaluated by a simple numeric count of the positive (+) stimulants to innovation and the negative (-) impediments to innovation that have been identified by the evaluation of the case study details. Table 4 presents the numeric count and Figure 1 presents the evaluation. The most effective innovation would occur when the stimulant (solid line) is as far from the axis as possible, and the impediment (dotted line) is as close to the central axis as possible. No work has yet been executed to quantify the proportional contribution of each feature. It treats all features in an identical manner. 


\begin{tabular}{|c|c|c|c|c|}
\hline IDENTIFIED* STIMULANTS & Prisons & Bridge & Military & School \\
\hline \multicolumn{5}{|c|}{ External Level } \\
\hline Clients & & & & $?$ \\
\hline \multicolumn{5}{|l|}{ Competition } \\
\hline \multicolumn{5}{|l|}{ Government } \\
\hline \multicolumn{5}{|l|}{ Professional bodies } \\
\hline \multicolumn{5}{|l|}{ Sharing Ideas in the Industry } \\
\hline Supply Chain & & & & $?$ \\
\hline \multicolumn{5}{|c|}{ Organisational Level } \\
\hline Encouragement of creative problem solving & & $?$ & & \\
\hline \multicolumn{5}{|l|}{ Fair, constructive judgement of ideas } \\
\hline \multicolumn{5}{|l|}{ Reward and recognition for creative work } \\
\hline $\begin{array}{l}\text { Mechanisms for developing and implementing } \\
\text { new ideas }\end{array}$ & & & $?$ & \\
\hline Clear shared Vision & & & & $?$ \\
\hline \multicolumn{5}{|l|}{ 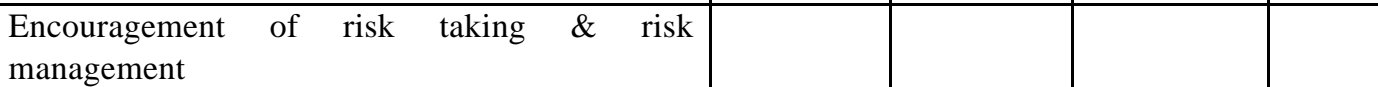 } \\
\hline \multicolumn{5}{|l|}{ Attracting creative people } \\
\hline \multicolumn{5}{|c|}{ Project Level } \\
\hline Supervisory role models & & & & $?$ \\
\hline Clear, appropriate goals & & & $?$ & $?$ \\
\hline \multicolumn{5}{|l|}{$\begin{array}{l}\text { Support for work group and individual } \\
\text { contributions from supervisor }\end{array}$} \\
\hline Motivation and commitment to the project work & & $?$ & & $?$ \\
\hline \multicolumn{5}{|l|}{ Diverse and suitable background of individuals } \\
\hline Good communication & & & & $?$ \\
\hline \multicolumn{5}{|l|}{ Openness to new ideas } \\
\hline \multicolumn{5}{|l|}{ Trust and help for others within the team } \\
\hline \multicolumn{5}{|l|}{ Constructive criticism of ideas } \\
\hline \multicolumn{5}{|c|}{ Job Role Level } \\
\hline Challenging and interesting tasks and projects & $?$ & $?$ & $?$ & $?$ \\
\hline Time control over work & & & & $?$ \\
\hline High autonomy & & & & $?$ \\
\hline \multicolumn{5}{|l|}{ Freedom } \\
\hline Access to appropriate materials and facilities, & & $?$ & & \\
\hline Access to necessary information & & & & $?$ \\
\hline Adequate funds & $?$ & $?$ & & $?$ \\
\hline \multicolumn{5}{|l|}{ Training and development } \\
\hline \multicolumn{5}{|l|}{ Creativity training } \\
\hline \multicolumn{5}{|l|}{ Creativity in Job Description } \\
\hline \multicolumn{5}{|l|}{ Conducive physical environment } \\
\hline Totals & +2 & +5 & +3 & +12 \\
\hline
\end{tabular}

Table 2: Detailed Stimulants of Creativity in PFI Case Studies.

- Identified as significant in accordance with the research protocol as identified above. 


\begin{tabular}{|c|c|c|c|c|}
\hline IDENTIFIED* IMPEDIMENTS & Prisons & Bridge & Military & School \\
\hline \multicolumn{5}{|c|}{ External Level } \\
\hline Client procurement route & $x$ & & $x$ & \\
\hline Coalition Nature of the Industry & $x$ & $x$ & $x$ & \\
\hline Lack of Communication & & $x$ & $x$ & \\
\hline Legislation & & & $x$ & \\
\hline \multicolumn{5}{|c|}{ Organisational Level } \\
\hline Internal political problems & $x$ & & & \\
\hline Destructive internal competition & & & $x$ & \\
\hline Harsh criticism of new ideas & $x$ & & & \\
\hline Conservatism and avoidance of risk & $x$ & & & \\
\hline Rigid structures & $x$ & & & \\
\hline Strict processes and procedures & $x$ & $x$ & $x$ & \\
\hline $\begin{array}{l}\text { Lack of mechanisms for developing and } \\
\text { implementing new ideas }\end{array}$ & $x$ & & $x$ & \\
\hline Lack of rewards and recognition & & & & \\
\hline \multicolumn{5}{|c|}{ Project Level } \\
\hline Format of project contract & $x$ & $x$ & $x$ & \\
\hline Rigid project demands & $x$ & $x$ & $x$ & \\
\hline Segmentation of project disciplines & $x$ & $x$ & $x$ & $x$ \\
\hline Poor project management & & & $x$ & \\
\hline \multicolumn{5}{|l|}{ Lack of communication and collaboration } \\
\hline Lack of openness and trust & & $x$ & $x$ & \\
\hline \multicolumn{5}{|c|}{ Job Role Level } \\
\hline Extreme time pressures & $x$ & & $x$ & \\
\hline Unrealistic expectations for productivity & $x$ & $x$ & $x$ & \\
\hline \multicolumn{5}{|l|}{ Distractions from creativity } \\
\hline Financial constraints & $x$ & $x$ & $x$ & $x$ \\
\hline Total & -14 & -9 & -15 & -2 \\
\hline
\end{tabular}

Table 3: Detailed Impediments to Innovation in PFI Case Studies.

${ }^{\mathrm{x}}$ Identified as significant in accordance with the research protocol as identified above.

\begin{tabular}{|l|c|c|c|c|}
\hline & Prisons & Bridge & Military & School \\
\hline $\begin{array}{l}\text { Identified } \\
\text { Stimulants }\end{array}$ & +2 & +5 & +3 & +12 \\
\hline $\begin{array}{l}\text { Identified } \\
\text { Impediments }\end{array}$ & -14 & -9 & -15 & -2 \\
\hline Total & -12 & -4 & -12 & +10 \\
\hline
\end{tabular}

Table 4: Summary of Collated Stimulants and Impediments by Project. 


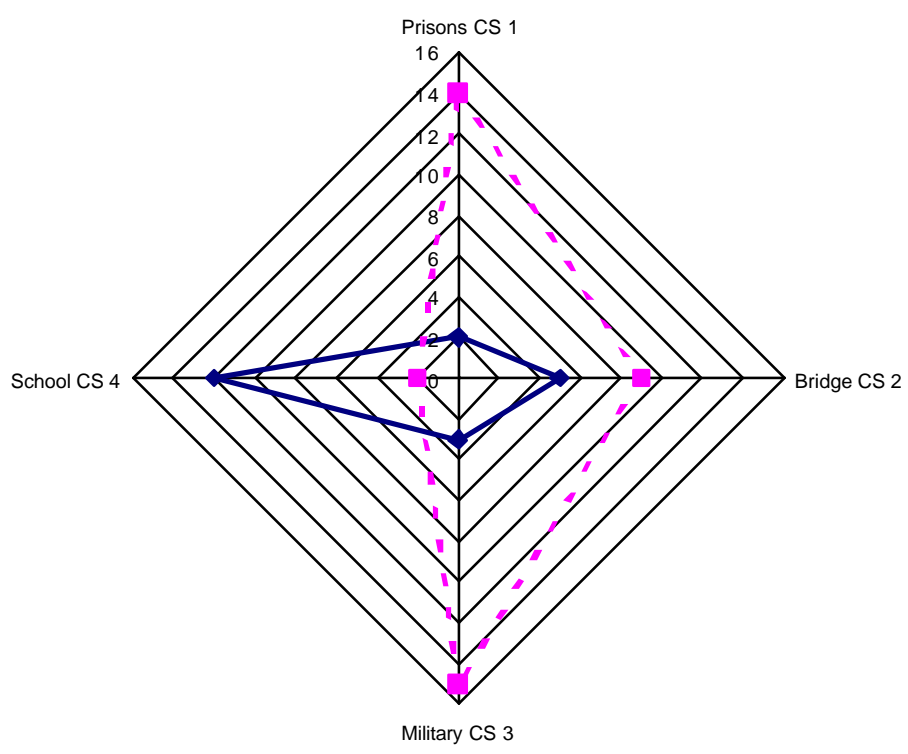

Figure 1: Comparison of Stimulants and Impediments to Innovation - by case study.

Where the impediments exceed the stimulants (as Prisons, Bridge and Military case studies) there is an indication that the 'incorporation of innovation' of the project has been impaired.

The simple numerical analysis by project is supplemented by case study analysis as presented in Table 5 and Figure 2. Table 5 presents the numeric aggregate count of the evaluation of stimulants and impediments by hierarchical level. The most effective innovation would again occur when the stimulant (solid line) is as far from the axis as possible, and the impediment (dotted line) is as close to the central axis as possible. However, in this case there is an indication that the inter-relationship between the levels is also important. Intuitively the impediments are more significant in the descending order of external, organisational, project and role, whilst the stimulants appear to be more important at the organisation and project levels than at the external or job role levels. No work has yet been executed to quantify the proportional contribution of each level. It treats all levels in an identical manner.

\begin{tabular}{|l|c|c|c|c|}
\hline & $\begin{array}{c}\text { External } \\
\text { Level }\end{array}$ & $\begin{array}{c}\text { Organisational } \\
\text { Level }\end{array}$ & Project Level & $\begin{array}{c}\text { Job Role } \\
\text { Level }\end{array}$ \\
\hline $\begin{array}{l}\text { Identified } \\
\text { Stimulants }\end{array}$ & +2 & +3 & +6 & +11 \\
\hline $\begin{array}{l}\text { Identified } \\
\text { Impediments }\end{array}$ & -8 & -10 & -13 & -9 \\
\hline Total & -6 & -7 & -7 & +2 \\
\hline
\end{tabular}

Table 5: Summary of Collated Stimulants and Impediments by Hierarchical Level 


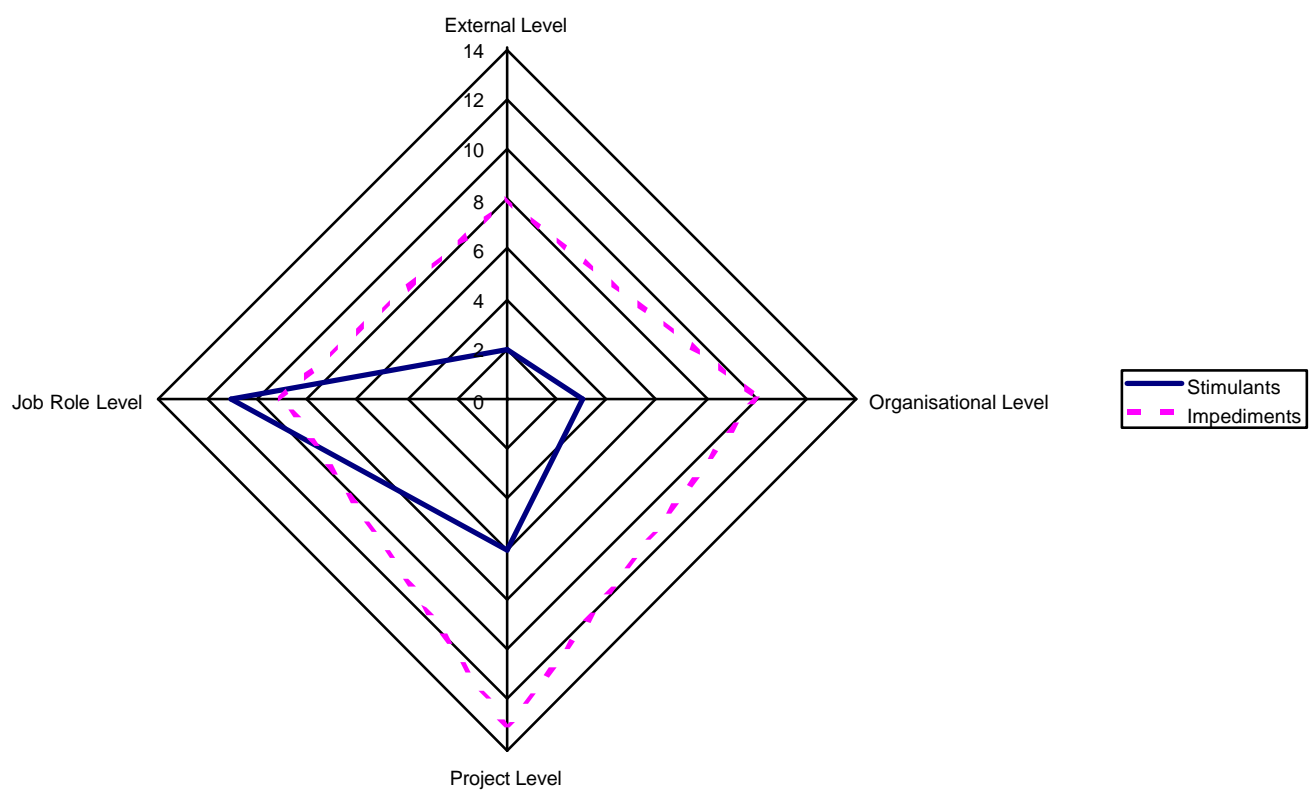

Figure 2: Hierarchical Aggregated Stimulants and Impediments to Innovation

\section{CONCLUSIONS}

The paper has identified the potential stimulants to creativity in PFI construction projects; it has also identified the potential impediments to creativity in PFI construction.

A theoretical model for the PFI construction industry of potential stimulants and impediments to creative behaviour in construction has been developed; it has been utilised to evaluate the incorporation of innovation of four previous case studies of PFI delivery.

The empirical study of the four cases suggests that to date the 'claimed' innovation associated with PFI/PPP is largely unrealised. There appears to be significant scope for innovation within the PFI/PPP projects.

In three of the case studies the numeric count of the impediments to innovation significantly outnumbers the stimulants and the aggregate impediments count exceeds the stimulants count at all but the Job-Role level. In three cases the construction contractor suffered significant cost over-runs; however, the Concessionaire with a Guaranteed Maximum Price (GMP) obtained virtually complete protection against these cost over-runs. The Client was equally protected by the concession arrangement.

In the cases of the prisons and military projects the stimulant and impediment count is very similar $(+2,-14:+3,-15)$, however, an evaluation of the 'success count' of each 
project, a crude measure of the perceived successful delivery of the projects, would yield a significantly different response, the prisons project being deemed overall, more successful, by all parties, than the military project. This is suggestive of an imbalance between the proportional contributions of individual features to the deemed success or otherwise of a project.

A further detail is that the higher level stimulants, i.e. those at the external and organisational level, are noticeable largely by their absence, whilst the impediments to innovation occur at all levels in the hierarchy. One interpretation of this feature is that the senior management of PFI projects have not evolved sufficiently to recognise the difference between a major 'traditional' project and a major PFI project. Hence the senior management have not changed their patterns of behaviour despite the change in procurement process. This feature of organisational culture is currently being further examined.

There appears to be some support within the analysis for the belief that innovation at the level of the job role is being achieved - it is surmised that this is the acclimatisation of individuals to the experience of the concept and operation associated with PFI.

The limitations associated with the findings are that a small sample of PFI projects have been utilised and no statistical analysis has been conducted. As stated previously each stimulant or impediment feature is treated equally. No ranking or relative weighting has been calculated. No ranking or weighting for the hierarchical levels has been calculated.

The recommendations, based upon the work completed, is that the model of impediments should be examined by the PFI parties and that the parties should verify that all impediments have been examined and that the parties are satisfied that all impediments have been removed as far as is practicable for a particular project. Equally, the stimulant model should be utilised in a similar manner and the parties should verify that the stimulants have been incorporated as far as is practicable.

Given this verification it is expected that a subsequent review of similar cases would yield an analysis that was predominantly positive, rather than the currently achieved balance that is predominantly negative.

It is the intention to further develop the model and to provide quantitative evaluation of the 'cost/benefit' of individual features of the model. Further evaluation of completed PFI projects utilising the model will give an indication of whether incorporation of innovation is improving as further experience of PFI/PPP is accumulated.

$\mathrm{PFI} / \mathrm{PPP}$ is developing world-wide as a procurement mechanism. The elimination of unintentional constraints upon the potential innovation within the PFI/PPP project and the inclusion of stimulants by the use of this model can improve project quality, reduce costs and improve delivery times by minimising the risks associated with this form of procurement. 


\section{BIBLIOGRAPHY}

Amabile, T.M. (1983). The Social Psychology of Creativity, Springer-Verlag: New York. USA.

Amabile, T.M. (1988). A model of creativity and innovation in organisations, in Staw, B.M. and Cummings, L.L. (eds) Research in Organisational BehaviourVol 10, JAI Press Greenwich, UK.

Amabile, T, M. (1996). Creativity in context. Westview Press: Oxford. UK

Amabile, T, M., Hennessey, B.A., and Grossman, B.S. (1986). Social influences on creativity: The effects of contracted-for reward, Journal of Personality and Social Psychology, 50, 14-23.

Amabile, T, M., Conti, R., Coon, H., Lazenby, J., and Herron, M. (1996). Assessing the work environment for creativity. Academy of Management Journal, 39, 5, 11541184.

Anderson, N., and West, M.A. (1994). The Team Climate Inventory, ASE: Windsor. UK.

Atkin, B. (1999). Innovation in the Construction Sector, European Council for Construction Research, Development and Innovation: Brussels. Belgium.

Barrett, P.S., Sexton, M.G., Miozzo, M., Wharton, A., and Leho, E. (2001). Base Report: Innovation in Small Construction Firms, University of Salford: Salford.UK.

Barron, F. (1969). Creative Person and Creative Process, Holt, Rinehart and Winston: New York. USA.

Barron, F., and Harrington, D. (1981). Creativity, intelligence, and personality, in Rosenzweig, M.R., and Porter, L.W. (eds), Annual Review of Psychology, 32, 439476.

Csikszentmihalyi, M. and Sawyer, R. K. (1995). Shifting the focus from individual to organisational creativity. In Ford, C.M., and Gioia, D.A. (eds.), Creative action in organisations: Ivory tower visions and real world voices, Sage: London. UK.

Cooper, R, Bruce, M, Wootton, A, Hands, D, Daly, L (2003). Managing Design in the Extended Enterprise. Building Research and Information 31(5), 367-378.

DeGraff, J., and Lawrence, K.A. (2002). Creativity at Work: Developing the right practices to make innovation happen, Jossey-Bass: San Francisco. USA.

De Lemos, T. \& Eaton, D. (2003) The Nature of PFI, Journal of Structured and Project Finance. (Vol. 9 Nr 1. Pp 59-75) Spring 2003 
De Lemos, T. \& Eaton, D. (2004) Risk Management in the Lusoponte concession- a case study of the two bridges in Lisbon, Portugal. International Journal of Project Management. Issue 22 P63-73

Drucker, P.F. (1986). Innovation and Entrepreneurship, Pan: London. UK.

Dulaimi, M.F., Ling, Y.Y. and Bajracharya, A. (2002) Enhancing integration and innovation in construction. Building Research and Information, 30(4), 237-47.

Eaton, D. (2000). A phenomenologically based contingent anatomy of competitive advantage within the construction industry, PhD Thesis, University of Salford: Salford.UK.

Eaton, D. (2001). A temporal typology for innovation within the construction industry, Journal of Construction Innovation, 1: 165-179.

Eaton, D. (2005). Quantifying Quality - PFI and the delivery of public services, Royal Institution of Chartered Surveyors, London. UK. Available online:http://www.rics.org/pfi

Egan, J. (1998). Rethinking Construction, HSMO: London. UK.

Egbu, C.O., Henry, J., Kaye, G.R., Quintas, P., Schumacher, T.R., and Young, B.A. (1998). Managing Organisational Innovations in Construction, Proceedings of the ARCOM Fourteenth Annual Conference, University of Reading: Reading. UK.

Fairclough, J. (2002). Rethinking Construction Innovation and Research. Department of Transport, Local Government and the Regions: London. UK.

Gann, D.M. (2000). Building Innovation: Complex constructs in a changing world, Thomas Telford: London. UK.

Gann, D.M. (2003). Innovation in the Built Environment, Construction Management and Economics, 21, 553-555.

Geroski, P. (1994). Market structure, corporate performance, and innovative activity. Clarendon Press: Oxford. UK.

Guilford, J.P. (1959). Traits of creativity. In Anderson, H.H. (ed), Creativity and its Cultivation, Harper: London. UK.

Isaksen, S.G., Lauer, K.J., Ekvall, G., and Britz, A. (2001). Perceptions of the Best and Worst Climates for Creativity, Creativity Research Journal, 13, 2, 171-184.

Kanter, R.M. (1983). The Change Masters: Corporate Entrepreneurs at Work, Allen and Unwin: London. UK.

King, N. (1990). Innovation at work the Research Literature, in West, M.A., and Farr J.L. (eds), Innovation and Creativity at Work, John Wiley and Sons: Chichester.UK.

Latham, M. (1994). Constructing the Team, HMSO: London. UK. 
Manseau, A., and Seaden, G. (2001). Innovation in Construction: An International Review of Public Policies, Spon Press: London. UK.

Nam C.H., and Tatum, C.B. (1997). Leaders and champions for construction innovation. Construction Management and Economics, 15, 3, 259-270.

Newton, P.W. (1999). Modeling Innovation in AEC: Understanding the Fourth Dimension of Competition. Available

online:http://www.ce.berkeley.edu/ tommelein/CEMworkshop/Newton.pdf.

Oldham, GR. \& Cummings, A. (1996) Employee Creativity: personal and Contextual Factors at Work, Academy of Management Journal, 39,3,607-634.

Porter, M. (1990). The competitive advantage of nations, The Free Press: New York. USA.

Pries, F. and Janszen, F. (1995). Innovation in the construction industry: the dominant role of the environment. Construction Management and Economics, 13, 1.

Robertson, M., Newell, S. and Swan, J. (1997) Professional Associations as 'Brokers' Facilitating Networking and the Diffusion of New ideas: Advantages and disadvantages, In Alvarez, JL. (ed) The Diffussion and Consumption of Business knowledge. EMOT Research programme publication, University of Warwick, Warwick. UK.

Scott, S.G. and Bruce, R.A. (1994). Determinants of innovative behaviour: A path model of individual innovation in the workplace. Academy of Management Journal, $37,580-607$.

Sexton, M.G. and Barrett, P.S. (2003). Appropriate innovation in small construction firms, Construction Management and Economics, 21, 623-633.

Slaughter, S.E. (1998). Models of construction innovation. Journal of Construction Engineering and Management, 124(3), 226-31.

Slaughter, S.E. (2000). Implementation of construction innovations. Building Research and Information, 28(1), 2-17.

Stein, M.I. (1991). Creativity is people, Leadership in Organisational Development Journal, 12 (6): 4-10.

Sturges, J. L., Egbu, C.O. and Bates M. B. (1999). Innovations in Construction, Proceedings of the 2nd International Conference on Construction Industry Development: Singapore.

Swan, W., Wood, G., McDermott, P., and Cooper, R. (2001). Trust in Construction:Conceptions of Trust in Project Relationships, Centre for Construction Innovation: Salford. UK.

Tatum, C.B. (1989). Organising to increase innovation in construction firms. Journal of Construction Engineering and Management, 115(4), pp. 602-17. 
Van de Ven, A. (1986). Central problems in the management of innovation. Management Science, 32, 590-607.

West, M.A. (2001). State of the art: Creativity and innovation at work. Psychologist, $13,9,460-464$.

Winch, G. (1998). Zephyrs of Creative Destruction: Understanding the Management of Innovation in Construction. Building Research and Information, 26, 268-279.

Winch, G. (2001). Innovation in the British Construction Industry: The Role of Public Policy Instruments, In Manseau, A., and Seaden, G. (eds) Innovation in Construction: An International Review of Public Policies, Spon Press: London. UK.

Winch, G. (2003). How innovative is construction? Comparing aggregated data on construction innovation and other sectors - a case of apples and pears, Construction Management and Economics, 21, 651-654.

Woodman, R.W., Sawyer, J.E., and Griffin, R.W. (1993). Toward a theory of organisational creativity, Academy of Management Review, 18, 293-321.

Zaltman, G., Duncan R., and Holbeck, J. (1973). Innovations and Organisations, John Wiley: New York. USA. 